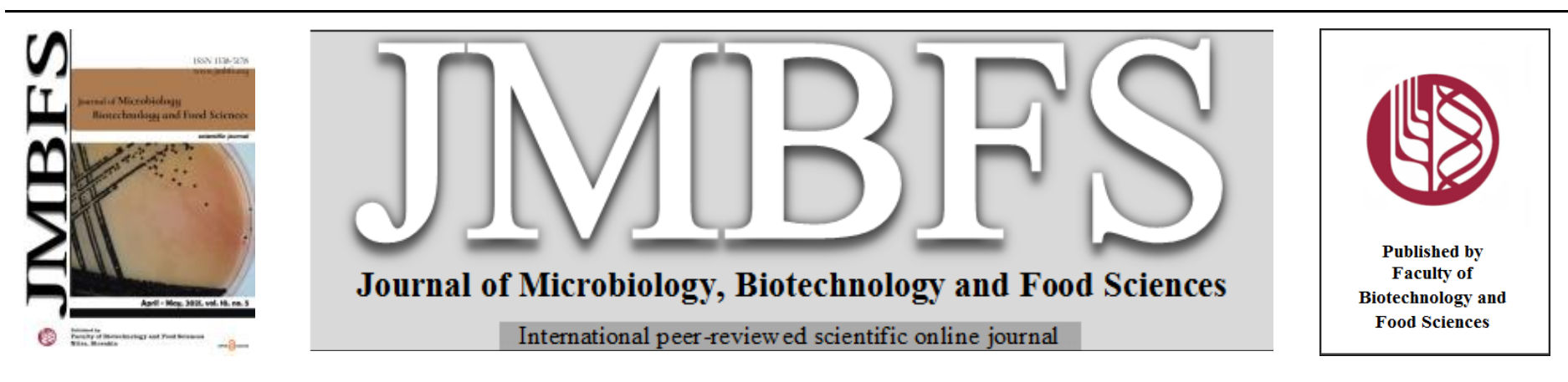

\title{
EFFECT OF HOUSEHOLD PROCESSING ON REMOVAL OF MULTI-CLASSES OF PESTICIDES FROM TOMATOES
}

\author{
Lima Ajeep $^{* 1}$, Zakaria Alnaser ${ }^{2}$, Mohammad Kheir Tahla $^{3}$
}

\author{
Address(es): \\ ${ }^{1}$ Damascus University, Faculty of Agricultural Engineering, Food Science Department, Institute of Pharmaceutical and Chemical Research, Scientific Studies and \\ Research Center, Damascus, Syria, phone number 00963112234947. \\ ${ }^{2}$ Damascus University, Faculty of Agricultural Engineering, Plant protection Department, Syria. \\ ${ }^{3}$ Damascus University, Faculty of Agricultural Engineering, Food Science Department, Syria.
}

*Corresponding author: limaajeep5@gmail.com

https://doi.org/10.15414/jmbfs.2015

\section{ARTICLE INFO}

Received 6. 7. 2019

Revised 1. 12. 2020

Accepted 4. 12. 2020

Published 1. 4. 2021

Regular article

OPEN OACCESS

\begin{abstract}
In this paper, twenty-two pesticide residues were monitored in tomatoes.72 marketed samples were extracted and purified with QuEChERS method, and analyzed with liquid and gas Chromatography. The mean recoveries ranged from 90.75\%to105.31\%. The relative standard deviation was $1 \%$ to $7.5 \%$. The limits of detection and quantification ranged from 0.0004 to $0.0231 \mathrm{mg} \cdot \mathrm{kg}^{-1}$ and 0.0012 to $0.0693 \mathrm{mg} \cdot \mathrm{kg}^{-1}$, and good linearity was obtained. Out of total analyzed samples, 34 samples (47.22\%) were contaminated with tested pesticide residues; out of which 10 samples (13.89\%) exceeded the maximum residue limits.

The effects of four processing techniques (washing with tap water, washing with solution of acetic acid, peeling and boiling) on the residual pattern of five insecticides (dimethoate, carbaryl, chlorpyrifos, cypermethrin and fenvalerate) and one herbicide $(2,4$ dichlorophenoxy acetic acid (2,4D)) were evaluated. The reaction of the pesticides depends obviously on the physico-chemical features and also on the systemic character of the pesticides. Both of the washings lowered clearly the residues for all detected pesticides with removing up to $63.08 \%$. Peeling was found to totally remove the residues of fenvalerate, carbaryl, cypermethrin and chlorpyrifos. Results obtained from the boiling indicated that a complete removal of 2,4D and dimethoate residues was finally achieved. In addition to that, the concentrations of cypermethrin and fenvalerate increased and processing factors above 1 were observed, the results can be seen as valuable base for monitoring of pesticides in tomatoes and supply more comprehension of residue demeanor after household
\end{abstract} processing. These implementations are important to protect consumer health from the damage of pesticide residues in food.

Keywords: pesticide residues, QuEChERS, household processing, food safety

\section{INTRODUCTION}

Tomatoes (Lycopersicon esculentum Mill.) constitute clearly an important part of the human's daily diet. This agricultural product is widely consumed by humans all over the planet (Certel et al., 2011). This is because it is a very rich sources of lycopene, and it is a main source of vitamins, trace minerals and antioxidants. On the other hand, pesticides are heavily used in the agricultural activities of tomatoes because of their ability to fight efficiently against insects and disease attacks (Lozowicka et al., 2015). Pesticides have various modes of action such as systemic actions (e.g., absorbed through the roots or other parts of the plant, such as leaves or stems) or contact (remain on the outside of the plant itself), and they follow several paths after contacting the surface of the plant (Jankowska et al., 2016).

The usage of incorrect or high dosage of pesticides causes the contamination of pesticides in their agricultural commodities, which may become a health risk to the consumer. Thus, residues can cause harmful effects on human health, especially when the contaminated food products are freshly eaten (Salghi $\boldsymbol{e t}$ al., 2012).

Numerous apprehensions about the human health are related with pesticides. They are ranging from short-term risks (for instance, nausea and headaches) to chronic risks such as birth defects, endocrine disruption, various cancers, and infertility (Alavanja et al., 2013) (Bempah et al., 2011). Young children, pregnant women, diabetics and elderly are the most vulnerable to short-term and chronic health apprehensions (Tahir et al., 2009), (Lozowicka, 2015).Thus, the monitoring of pesticide residues in fruits become a basic demand for consumers (Han et al., 2013), and databases are formed for assisting the evaluation of the level of pesticide residues and residue intake.

Each country sets its own maximum residue limits (MRLs), and hence residue levels that are acceptable in one country may not be acceptable in another one (Torres et al., 1996). The required quantities of application may differ, under various climatic and agricultural conditions, from country to country, and between regions of the same country (Torres et al., 1997), (Zawiyah et al.,
2007). In Syria, there are no defined MRLs for agricultural commodities, but limits issued by the European Union or by Food and Agriculture Organization can be used as benchmarks, so such study is important for establishing MRLs and for assessing the amount of pesticides in Syrian agricultural fields.

The nature and concentration of pesticide residues in food have varied during commercial or home processing (Li et al., 2011). Food processors and scientists have been interested, for long time, in the effect of household processing on pesticide residues in food (Aguilera et al., 2012; Cabras and Angioni, 2000; Amvrazi, 2011; Keikotlhaile et al., 2010; Shabeer et al., 2015; Bonnechere et al., 2012; Zhao et al., 2014). However, the effect of household processing on economically important agricultural commodities of Syria, such as tomato, is less known. Additionally, the processing factor (denoted by PF, and defined as the ratio between the residues amount in the processed food commodity and that in the raw material) is the basic parameter used to quantify the processing efficiency (Jankowska et al., 2016). Many PF values remain unknown. In addition, there are no MRLs for the processed commodities; so, this value must be determined precisely. It becomes more necessary when researchers aim to accomplish a risk assessment for a pesticide in processed agriculture commodities (Rawn et al., 2008).

The QuEChERS method was used to sample preparation because it has many benefits over other traditional extraction methods since it achieves. High recovery values (above 85\%) for various polar and volatile pesticides. Also, this method is characterized by: low solvent consumption, safe, cheap and effective. The method is also very rugged because of removing organic acids and other impurities during the clean-up of extract, high quality results in a simple, fast and an inexpensive process (Rohan et al., 2012), (Lehotay, 2007). Lately, the QuEChERS method for multiple pesticides in vegetables and fruits has received the uniqueness as the Official Method of AOAC International (Lehotay et al., 2005).

The methods of gas chromatography (GC) with flame ionization detector (FID), electron capture detector (ECD), HPLC with UV detector and gas chromatography/mass spectrometry (GC/MS) with selected ion monitoring (SIM) 
were chosen for quantifying the quantities of pyrethroid, organophosphate, carbamate and other classes of pesticides, because of high resolution ability. In addition, their detectors are characterized by high selectivity and sensitivity. Confirmatory analysis was needed in order to prevent any misinterpretation of results (Ucles et al., 2014; Colume et al., 2001a, b; Pico et al., 2007).

Therefore, this study aims to identify pesticide residues and their levels in tomatoes commonly consumed in Damascus, Syria. Also four different household processing techniques were studied in order to find out the most effective one for removing pesticide residues, and for evaluating the performance of these processing techniques in terms of the concentration of the most commonly detected pesticides - that are above MRLs - in samples.

\section{MATERIAL AND METHODS}

\section{Chemicals and Solvents}

Pesticide standards of high purity were obtained from Dr Efrenstorfer GmbH(Augsburg, Germany), and Riedel de Haen (Seelze, Germany). This research make use of, as Pesticide standards, lambda cyhalothrin, cypermethrin, Fenarimol, permethrin, deltamethrin, fenvalerate, methomyl, imidacloprod, propoxur, bentazon, chlorpyrifos, carbaryl, 2,4 dichlorophenoxy acetic acid (2.4 D), azinphos ethyl, tetradifon, methidathion, bromofos, fenitrathion, parathion methyl, dimethoate, monocrotophos, methamidophos. Tetradecane (C14) was considered as internal standard. HPLC-grade acetonitrile, water, Acetone and acetic acid (96\%) wereobtained from Merck (Darmstadt, Germany), anhydrous MgSO4(99.5\%), Na citrate tribasic dehydrate (99.8\%), Na citrate dibasic sesquihydrate (99.7\%), $\mathrm{NaCl}(99.5 \%)$, Primary Secondary Amine (PSA) and Graphitized carbon black (GCB) were obtained from Sigma Aldrich (St Louis, MI, USA). The formic acid (88\% purity) was obtained from J. T. Baker (Phillipsburg, NJ, USA). Standard solutions were obtained by appropriate dilution of the stock solutions (1000 mg. $\mathrm{L}^{1}$ ) in Acetone (which is injected to gas chromatography) and acetonitrile (which is injected to liquid chromatography). These solutions were stored at $-25^{\circ} \mathrm{C}$.

\section{Sampling}

For the evaluation of pesticide residues, 72 samples of tomato were collected in July and august during two years 2017-2018 from three main fruit markets in Damascus (Mezzeh, Al-Zabltani, and old Hall). The size of the sample was around $10 \mathrm{~kg}$. The raw commodity was prepared as the analytical sample for determining the pesticide residues according to the Codex Alimentarius, Volume 2A, part 1-2000. Each sample was divided into five parts (approximately $2 \mathrm{~kg}$ each); the first part was cleaned to remove suspended impurities and soil, divided into tiny parts. The second was washed with tap water for a $5 \mathrm{~min}$ and then divided into small parts. The third one was soaked with $2 \%$ acetic acid solution for $15 \mathrm{~min}$, and then washed with tap water to remove the effect of acidic water The forth was skinned with a special knife. Each $200 \mathrm{~g}$ of fifth part were put into a stainless steel bowl and placed into $1 \mathrm{~L}$ of boiling water at $100^{\circ} \mathrm{C}$ for $5 \mathrm{~min}$, after samples preparation and processing, each part was homogenized, and then frozen at $-20^{\circ} \mathrm{C}$ until the date of the analysis (Codex Alimentarius, 2000).

\section{Sample Extraction and Clean-Up}

The QuEChERS method as defined in EN 15662:2008 (European Standard, 2008) was applied to sample preparation. The amount of $10 \mathrm{~g}$ of homogenized sample was placed in a $50 \mathrm{ml}$ of PTEF centrifuge tube; $10 \mathrm{ml}$ of acetonitrile was added and shacked vigorously for $1 \mathrm{~min} .4 \mathrm{~g}$ of magnesium sulphate, $1.0 \mathrm{~g}$ of sodium chloride, $1.0 \mathrm{~g}$ trisodium citrate dehydrate and $0.5 \mathrm{~g}$ disodium hydrogencitrate sesquihydrate were added, shacked vigorously for $1 \mathrm{~min}$ and centrifuged at $4000 \mathrm{rcf}$ for $5 \mathrm{~min}$.Supernatant was pulled into another tube having $150 \mathrm{mg}$ of primary, secondary amine (PSA), $45 \mathrm{mg}$ of graphite carbon black (GCB) and $900 \mathrm{mg}$ of magnesium sulphate. It was shacked for 30 seconds and centrifuged at 4000rcf for $5 \mathrm{~min}, 5 \mathrm{ml}$ supernatant was transferred to a vail and acidified by adding $50 \mu 15 \%$ solution of formic acid in acetonitrile. Then diluted with mobile phase for HPLC analysis, and with Acetone for GC analysis.

\section{Analytical Technique}

Gas chromatography/mass spectrophotometer (GC/MS) was used for pyrethroid and organophosphate pesticides, 2.4.D and tetradifon identification: For the analysis, a Shimadzu (QP 2010 GC-MS) gas chromatography equipped with mass selective detector as well as a TRP-5-MS column (60m long, internal diameter of $0.25 \mathrm{~mm}$, and film thickness of $0.25 \mu \mathrm{m})$ was used. Sample injection was completed in the direct mode, with an injector temperature of $270{ }^{\circ} \mathrm{C}$ and an interface temperature of $225^{\circ} \mathrm{C}$. The temperature of the oven was programmed from an initial value of $90{ }^{\circ} \mathrm{C}$, ramped to $150{ }^{\circ} \mathrm{C}$ at $10{ }^{\circ} \mathrm{C} / \mathrm{min}$ for $2 \mathrm{~min}$, and to $200{ }^{\circ} \mathrm{C}$ at $10{ }^{\circ} \mathrm{C} / \mathrm{min}$ for $3 \mathrm{~min}$, and was raised to 260 ${ }^{\circ} \mathrm{C}$ at $10{ }^{\circ} \mathrm{C} / \mathrm{min}$ for $3 \mathrm{~min}$, then was raised to $300{ }^{\circ} \mathrm{C}$ at $20^{\circ} \mathrm{C} / \mathrm{min}$ for $33 \mathrm{~min}$. The used carrier gas was Helium with a constant flow rate of $1 \mathrm{ml} / \mathrm{min}$. In addition, Electron ionization was used at $70 \mathrm{eV}$ in selective ion monitoring (SIM) whereas full-scan modes between $50 \mathrm{~m} / \mathrm{z}$ and $500 \mathrm{~m} / \mathrm{z}$ was used for the detection of different analytes (table 1,2), Fig $(1,2)$

Table 1 Organophosphate pesticides and tetradifon retention times, molecular mass and selected ions for accomplishing GC-MS (SIM)

\begin{tabular}{llll}
\hline Pesticide & Retention times(min) & Molecular mass & Selected ions,m/z \\
\hline Methamidophos & 10.5 & 141 & $64-79-94$ \\
\hline Monocrotophos & 19.21 & 223 & $127-67-192$ \\
\hline Dimethoate & 20.07 & 229 & $87-125-58$ \\
\hline Methyl parathion & 22.65 & 263 & $125-109-63$ \\
\hline Fenitrothion & 23.6 & 277 & $125-109-260-79$ \\
\hline Chlorpyrifos & 24.12 & 349 & $197-97-314-125$ \\
\hline Bromofos & 24.8 & 364 & $125-331-213-109$ \\
\hline Methidathion & 26.16 & 302 & $145-85-93-125$ \\
\hline Tetradifon & 31.84 & 354 & $159-227-111-127$ \\
\hline Azinphos-ethyl & 33.46 & 345 & $132-160-77-104$ \\
\hline
\end{tabular}

Gas chromatography/flame ionization detector (FID) was used for organophosphate pesticides and tetradifon quantification: A Shimadzu (C2010GC-FID) and TRP-5- column (60m long, internal diameter of $0.25 \mathrm{~mm}$, and film thickness of $0.25 \mu \mathrm{m}$ ) was used for analysis, with an injector temperature of $270{ }^{\circ} \mathrm{C}$, and a detector temperature of $300^{\circ} \mathrm{C}$. The temperature of the oven was programmed from an initial value of $120{ }^{\circ} \mathrm{C}$ for $2 \mathrm{~min}$, ramped to $200{ }^{\circ} \mathrm{C}$ at $4{ }^{\circ} \mathrm{C} / \mathrm{min}$ for $2 \mathrm{~min}$, and to $300^{\circ} \mathrm{C}$ at $5^{\circ} \mathrm{C} / \mathrm{min}$ for $10 \mathrm{~min}$. Helium was used as a carrier gas with a constant flow rate of $40 \mathrm{ml} / \mathrm{min}, 400 \mathrm{ml} / \mathrm{min}$ for air flow rate, an injection volume of $1 \mu \mathrm{l}$ was used in splitless mode as shown in Fig 3

Table 2 pyrethroid pesticides and2,4,D retention times, molecular mass and selected ions for accomplishing GC-MS (SIM)

\begin{tabular}{llll}
\hline Pesticide & Retention times(min) & Molecular mass & Selected ions,m/z \\
\hline 2-4 D & 20.15 & 220 & $62-164-220$ \\
\hline Lambda-cyhalothrin & 32.3 & 449 & $208-197-181$ \\
\hline Fenarimol & 33.17 & 330 & $107-219-139$ \\
\hline permethrin & 33.9 & 390 & $165-163-183$ \\
\hline Permethrin isomer1 & 34.2 & 390 & $165-163-183$ \\
\hline Cypermethrin & 36.1 & 415 & $181-165-163$ \\
\hline Cypermethrin isomer1 & 36.3 & 415 & $181-165-163$ \\
\hline Cypermethrin isomer2 & 36.6 & 415 & $181-165-163$ \\
\hline Fenvalerate & 39.0 & 419 & $181-125-167$ \\
\hline Fenvalerate isomer1 & 39.7 & 419 & $181-125-167$ \\
\hline Deltamithrin & 41.9 & 503 & $181-251-253$ \\
\hline
\end{tabular}


Gas chromatography/ micro-electron capture detector (GC- $\mu$ ECD) used for pyrethroid pesticides quantification: Shimadzu2014 GC- $\mu$ ECD, the compounds were separated on a 5\% phenyl 95\% dimethylsiloxane fused-silica capillary column $(60 \mathrm{~m}, 0.25 \mathrm{~mm}$ i.d., $0.25 \mu \mathrm{m}$ film thickness). The injector and detector temperatures were set to $280{ }^{\circ} \mathrm{C}$ and $300{ }^{\circ} \mathrm{C}$, respectively. The oven temperature was programmed $300{ }^{\circ} \mathrm{C}$ for $(60 \mathrm{~min})$. An injection volume of $1 \mu \mathrm{l}$ was used in split injection mode. Helium was used as a carrier gas with a constant flow rate of $0.97 \mathrm{ml} / \mathrm{min}$ as shown in Fig 4 .

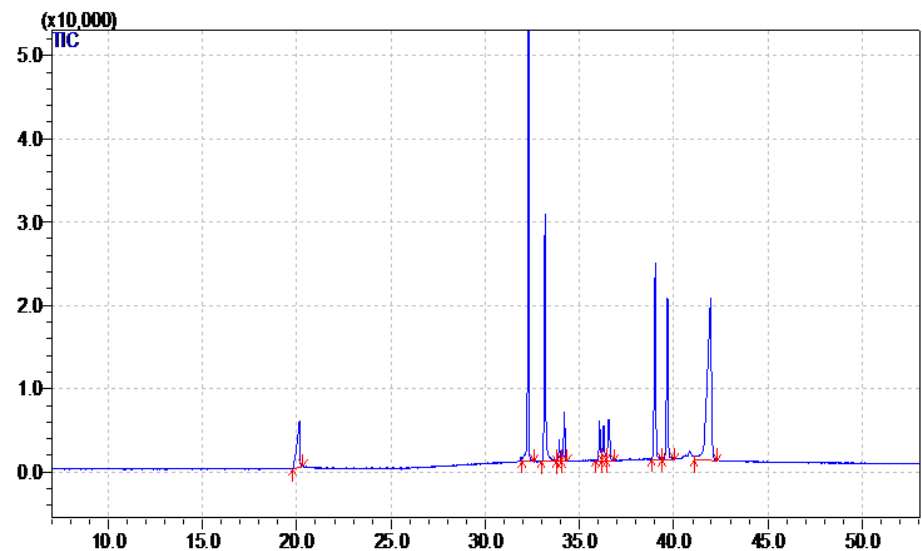

Figure 1 GC-MS Chromatogram of standards organo- Phosphate Pesticides and tetradifon

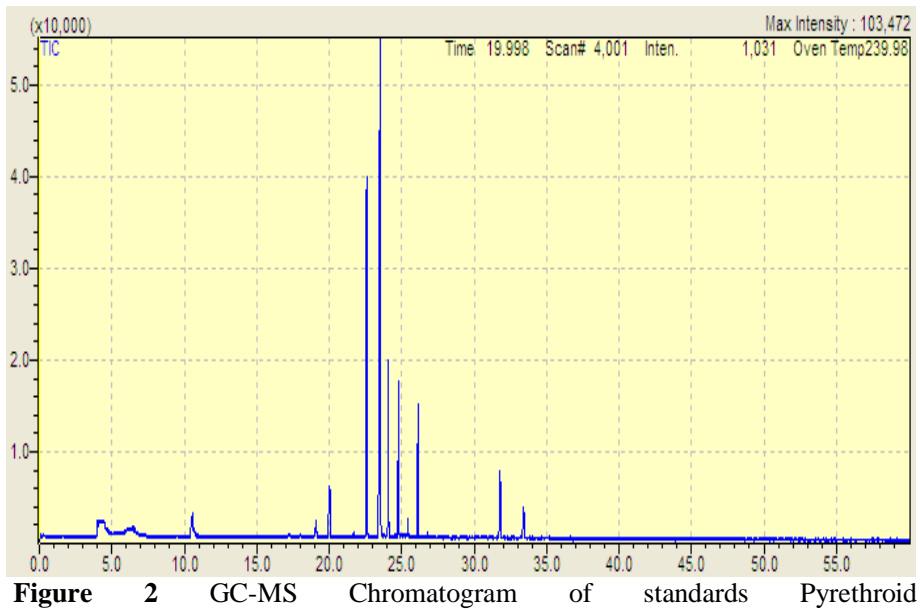

pesticides and 2,4,D

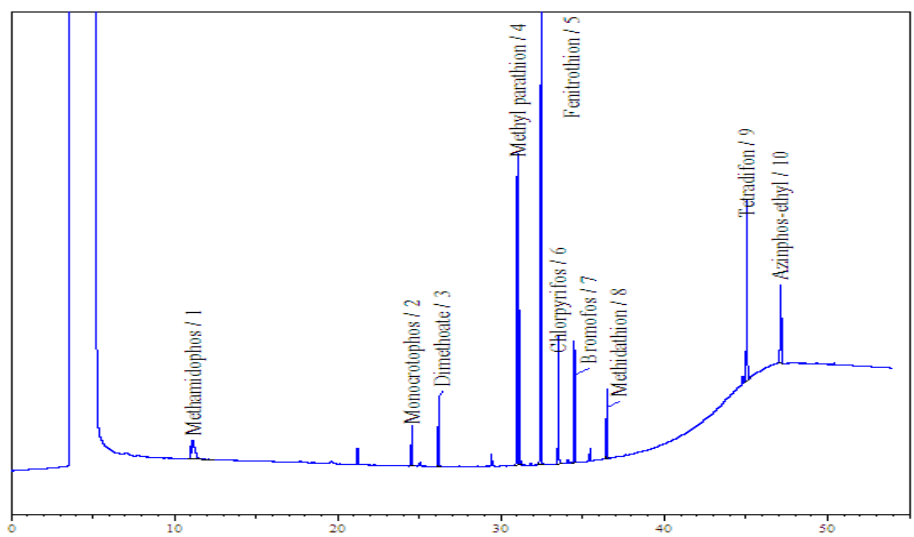

Figure 3 GC-FID Chromatogram of standards organo- phosphate Pesticides and tetradifon

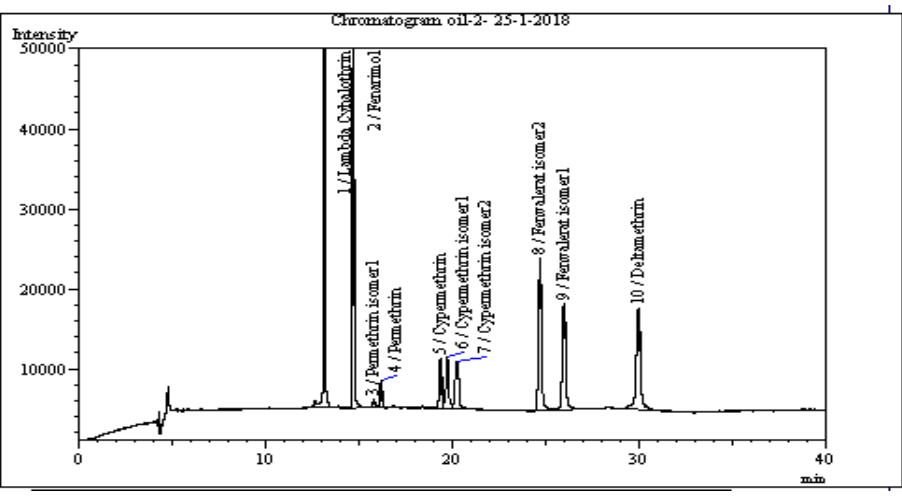

Figure 4 GC-ECD Chromatogram of standards Pyrethroid pesticides

High Performance Liquid chromatography coupled with ultra violet (UV) detector was used for carbamate and other pesticides determination: Agilent Technologies, Infinity1260, G1362A(HPLC-UV). The separation was carried out on a SHISEIDO F/NE CHEM/CALS Capcell pack C18column AG120 $(250 \mathrm{~mm} \times$ $4.6 \mathrm{~mm} \mathrm{ID}, 5 \mu \mathrm{m})$. The mobile phase was $40 \%$ acetonitrile and $60 \%$ de-ionized water (contained $0.02 \%$ phosphoric acid), flow rate $1 \mathrm{ml} / \mathrm{min}$, wavelength $230 \mathrm{~nm}$, injection volume $20 \mu 1$ and Oven temperature $40^{\circ} \mathrm{C}$, as summarized in Table 3 and shown in Fig 5 .

\section{Method validation and quality assurance}

Quality assurance of the method used to analyze samples was completed for the following parameters which were performed in a complete accordance with the European Commission guidelines (2016): recovery, linearity, precision, limit of quantification (LOQ) and limit of detection (LOD). The assessment of recovery was, on the other hand, performed by using a mixture of the examined pesticides at fortification levels of $0.05,0.1,0.5,1$ and $2 \mathrm{mg} \cdot \mathrm{kg}^{-1}$ with 5 replications. The precision of this method was calculated in terms of repeatability while considering relative standard deviation (RSD), also by 5 replicated analyses at five fortification levels. In order to evaluate linearity, the extraction solutions from blank samples were fortified with multi-standard solutions of $0.05,0.1$, $0.5,1$ and $2 \mathrm{mg} \cdot \mathrm{kg}^{-1}$, analyzed in triplicate at each level. The limits of detection (LOD) and of quantification (LOQ) were assessed as the lowest pesticide concentration level calculated by 3 times and 10 times the signal to- noise ratio respectively (European Commission, 2016). The reagent blank sample was, in addition, frequently run to make sure there is no interference due to pollution from the chemicals, solvents or apparatus used.

Table 3 Carbamate and other pesticides, retention Times, molecular mass for accomplishing HPLC-UV

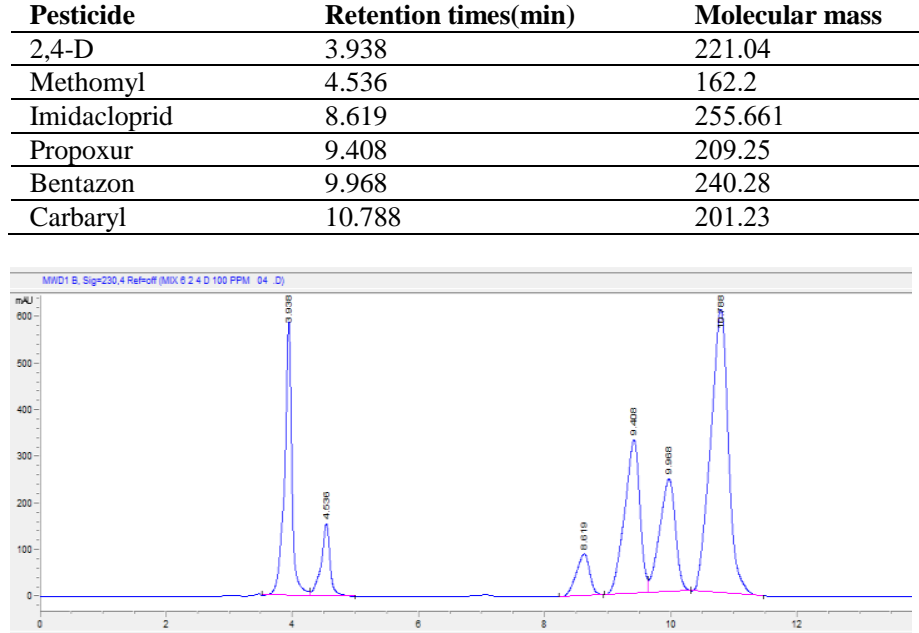

Fig 5 HPLC-UV Chromatogram of standards carbamate and other pesticides

Table 4 shows that recovery percentages were within the range $90.75 \%$ to $105.31 \%$ and the precision according to the relative standard deviations (RSD \%) ranged from $1 \%$ to $7.5 \%$, under replicated conditions. These values are acceptable according to the recommendations of the European Commission (2016). The LOD and LOQ ranged from 0.0004 to $0.0231 \mathrm{mg} \cdot \mathrm{kg}^{-1}$ and from 0.0012 to $0.0693 \mathrm{mg} \cdot \mathrm{kg}^{-1}$. Good linearity was gotten within the range from 0.01 to $2.0 \mathrm{mg} . \mathrm{kg}^{-1}$ with coefficients of correlation $\left(\mathrm{R}^{2}\right)$ above 0.990 . There were no residues in the blank tomato samples at the LOD of method 
Table 4 Parameters of the method used in the analysis

\begin{tabular}{llllll}
\hline Pesticide & LOD $\left(\mathbf{m g . k}^{-\mathbf{1}}\right)$ & $\mathbf{L O Q}\left(\mathbf{m g} . \mathbf{k g}^{-\mathbf{1}}\right)$ & $\mathbf{R}^{\mathbf{2}}$ & $\mathbf{R e c o v e r y} \mathbf{( \% )}$ & $\mathbf{R S D ( \% )}$ \\
\hline Methamidophos & 0.003 & 0.009 & 0.998 & 96.52 & 1.18 \\
\hline Monocrotophos & 0.0026 & 0.0078 & 0.9988 & 98.49 & 1.43 \\
\hline Dimethoate & 0.002 & 0.006 & 0.9975 & 93.36 & 2.3 \\
\hline Methyl parathion & 0.0016 & 0.0048 & 0.9992 & 99.67 & 1.38 \\
\hline Fenitrothion & 0.0015 & 0.0045 & 0.9988 & 92.22 & 3.55 \\
\hline Chlorpyrifos & 0.0018 & 0.0054 & 0.9986 & 100.31 & 2.85 \\
\hline Bromofos & 0.0018 & 0.0054 & 0.9985 & 101.1 & 5.72 \\
\hline Methidathion & 0.0019 & 0.0057 & 1.00 & 96.35 & 3.11 \\
\hline Tetradifon & 0.0017 & 0.0051 & 1.00 & 101.41 & 1.09 \\
\hline Azinphos-ethyl & 0.0018 & 0.0054 & 1.00 & 99.03 & 2.89 \\
\hline Lambda-cyhalothrin & 0.0004 & 0.0012 & 0.9989 & 97.6 & 4.0 \\
\hline Fenarimol & 0.0011 & 0.0033 & 0.9988 & 90.75 & 3.82 \\
\hline permethrin & 0.0231 & 0.0693 & 0.999 & 95.77 & 1.29 \\
\hline Permethrin isomer1 & 0.0084 & 0.0252 & 0.9992 & 94.32 & 1.19 \\
\hline Cypermethrin & 0.0091 & 0.0273 & 0.997 & 100.16 & 7.5 \\
\hline Cypermethrin isomer1 & 0.0093 & 0.0279 & 0.9986 & 100.84 & 1.48 \\
\hline Cypermethrin isomer & 0.0095 & 0.0285 & 0.9985 & 99.86 & 6.06 \\
\hline Fenvalerate & 0.0015 & 0.0045 & 0.9971 & 101.67 & 4.86 \\
\hline Fenvalerate isomer1 & 0.0035 & 0.0105 & 0.999 & 99.51 & 6.46 \\
\hline Deltamithrin & 0.0026 & 0.0078 & 0.9984 & 97.71 & 3.4 \\
\hline 2,4-D & 0.0009 & 0.0027 & 0.997 & 103.09 & 2.10 \\
\hline Methomyl & 0.003 & 0.009 & 0.999 & 100.54 & 2.95 \\
\hline Imidacloprid & 0.0071 & 0.0213 & 0.9988 & 100.06 & 1.00 \\
\hline Propoxur & 0.0020 & 0.006 & 0.999 & 104.98 & 4.67 \\
\hline Bentazon & 0.0029 & 0.0087 & 0.9992 & 101.28 & 1.46 \\
\hline Carbaryl & 0.0009 & 0.0027 & 0.999 & 105.31 & 3.97 \\
\hline LOD - limits of detection.LOQ -limit of quantification. R $^{2}$ - coefficients of correlation.RSD - relative standard deviations. & \\
\hline
\end{tabular}

\section{STATISTICAL ANALYSIS}

Data are expressed as mean \pm standard deviation and subjected to the ANOVA contrast analysis. Means were compared for significance by LSD method at P < 0.05 when comparing the four proposed treatments for removal of the pesticides. (Steel and Torrie, 1980)

\section{RESULTS AND DISCUSSION}

In this study, the residues of 22 studied pesticides were evaluated in 72 sample of tomato from three markets in Damascus, Syria. In the analyzed samples, 8 pesticides belonging to various chemical category (organophosphates, Pyrethroids, carbamates, Phenoxy and neonicotinoids) were detected. The external standard method was applied to calculate the quantity of each pesticide The concentration of the pesticides analyses in unprocessed samples and the MRLs determined by European Union are summarized in Table 5.Out of the tota 72 samples analyzed, 34 samples $(47.22 \%)$ contained detectable amount of pesticide residues, while in the remaining 38 samples $(52.78 \%)$ no pesticide residues were detected. Out of which 10 samples (13.89\%) exceeded the MRLs established by (European Union, 2014).

As shown by the data in Table 5 , the most frequently detected pesticide was imidacloprid (25\% of 72 samples), although imidacloprid is neonicotinoid insecticide and classified, in general, as moderately hazardous. Neonicotinoid pesticide has been often related with human neurotoxicity. The Commission implementing regulations amending the conditions of approval of imidacloprid have been published in the official journal of European union in May 2018 and completely banned the outdoor uses of imidacloprid (European Commission,2018). Followed by the chlorpyrifos (23.08\% of total samples), that was found in 12 samples, as well as cypermethrin $(17.31 \%)$. Based on the results, concentration of Dimethoate exceeded its MRL in 3 samples. Two samples had residues exceeding their MRL for 2,4D and Cypermethrin, while Carbaryl, chlorpyrifos and fenvalerate exceeded their limits in one.

Table 5 Concentration ranges of pesticide residues in 72 tomatoes samples analyzed

\begin{tabular}{llcc}
\hline $\begin{array}{l}\text { Sample } \\
\text { No. }\end{array}$ & Pesticides & $\begin{array}{c}(\text { Concentration }(\mathbf{m g . k g} \\
\mathbf{\pm} \mathbf{S D})\end{array}$ & EU MRL \\
\hline 1 & Imidacloprid & $0.131 \pm 0.015$ & 0.5 \\
\hline \multirow{2}{*}{6} & Dimethoate & $\mathbf{( 0 . 0 8 9} \pm \mathbf{0 . 0 0 4})^{*}$ & 0.01 \\
\cline { 2 - 4 } & Cypermethrin & $0.124 \pm 0.002$ & 0.5 \\
\hline 7 & Imidacloprid & $0.096 \pm 0.005$ & 0.5 \\
\hline 10 & Imidacloprid & $0.33 \pm 0.013$ & 0.5 \\
\hline \multirow{2}{*}{13} & Carbaryl & $\mathbf{( 0 . 1 3} \pm \mathbf{0 . 0 0 8})^{*}$ & 0.01 \\
\cline { 2 - 4 } & Chlorpyrifos & $0.0083 \pm 0.0003$ & 0.01 \\
\hline \multirow{2}{*}{14} & Imidacloprid & $0.21 \pm 0.021$ & 0.5 \\
\cline { 2 - 4 } & Monocrotophos & $0.0096 \pm 0.0005$ & 0.01 \\
\cline { 2 - 4 } & Chlorpyrifos & $0.009 \pm 0.0003$ & 0.01 \\
\hline 16 & Cypermethrin & $0.095 \pm 0.0061$ & 0.5 \\
\hline
\end{tabular}

\begin{tabular}{|c|c|c|c|}
\hline 21 & Imidacloprid & $0.11 \pm 0.004$ & 0.5 \\
\hline 22 & Dimethoate & $(0.07 \pm 0.001)^{*}$ & 0.01 \\
\hline \multirow{2}{*}{26} & Dimethoate & $(0.16 \pm 0.02)^{*}$ & 0.01 \\
\hline & Imidacloprid & $0.32 \pm 0.006$ & 0.5 \\
\hline 27 & Cypermethrin & $0.11 \pm 0.004$ & 0.5 \\
\hline \multirow{3}{*}{28} & Chlorpyrifos & $0.009 \pm 0.0001$ & 0.01 \\
\hline & Imidacloprid & $0.17 \pm 0.003$ & 0.5 \\
\hline & Cypermethrin & $0.098 \pm 0.004$ & 0.5 \\
\hline 35 & Chlorpyrifos & $(0.23 \pm 0.006)^{*}$ & 0.01 \\
\hline 36 & Imidacloprid & $0.36 \pm 0.01$ & 0.5 \\
\hline 38 & Cypermethrin & $0.15 \pm 0.006$ & 0.5 \\
\hline 39 & Chlorpyrifos & $0.0071 \pm 0.0004$ & 0.01 \\
\hline \multirow{2}{*}{43} & Imidacloprid & $0.25 \pm 0.009$ & 0.5 \\
\hline & Chlorpyrifos & $0.007 \pm 0.0002$ & 0.01 \\
\hline \multirow{2}{*}{44} & $2,4 \mathrm{D}$ & $(0.15 \pm 0.022)^{*}$ & 0.05 \\
\hline & Dimethoate & $0.008 \pm 0.0004$ & 0.01 \\
\hline 45 & Cypermethrin & $0.087 \pm 0.011$ & 0.5 \\
\hline 47 & Fenvalerate & $(0.79 \pm 0.036)^{*}$ & 0.1 \\
\hline \multirow{3}{*}{48} & $2,4 \mathrm{D}$ & $0.012 \pm 0.004$ & 0.05 \\
\hline & Imidacloprid & $0.174 \pm 0.063$ & 0.5 \\
\hline & Chlorpyrifos & $0.0074 \pm 0.001$ & 0.01 \\
\hline 51 & Monocrotphos & $0.0083 \pm 0.0004$ & 0.01 \\
\hline \multirow{4}{*}{53} & Carbaryl & $0.0076 \pm 0.0002$ & 0.01 \\
\hline & Imidacloprid & $0.081 \pm 0.003$ & 0.5 \\
\hline & Cypermethrin & $(0.95 \pm 0.004)^{*}$ & 0.5 \\
\hline & Chlorpyrifos & $0.0068 \pm 0.0007$ & 0.01 \\
\hline 54 & Fenvalerate & $0.065 \pm 0.0001$ & 0.1 \\
\hline \multirow{3}{*}{55} & Chlorpyrifos & $0.008 \pm 0.0001$ & 0.01 \\
\hline & Cypermethrin & $0.65 \pm 0.011)^{*}$ & 0.5 \\
\hline & Fenvalerate & $0.069 \pm 0.002$ & 0.1 \\
\hline 56 & Chlorpyrifos & $0.0078 \pm 0.0001$ & 0.01 \\
\hline \multirow{2}{*}{59} & $2,4 \mathrm{D}$ & $0.018 \pm 0.007$ & 0.05 \\
\hline & Monocrotphos & $0.0084 \pm 0.0001$ & 0.01 \\
\hline 60 & Imidacloprid & $0.15 \pm 0.007$ & 0.5 \\
\hline 62 & Cypermethrin & $0.11 \pm 0.005$ & 0.5 \\
\hline \multirow{2}{*}{65} & Chlorpyrifos & $0.0067 \pm 0.0002$ & 0.01 \\
\hline & $2,4 \mathrm{D}$ & $(0.08 \pm 0.005)^{*}$ & 0.05 \\
\hline 67 & Carbaryl & $0.0076 \pm 0.0002$ & 0.01 \\
\hline 69 & Chlorpyrifos & $0.0069 \pm 0.0002$ & 0.01 \\
\hline 70 & Imidacloprid & $0.095 \pm 0.003$ & 0.5 \\
\hline 72 & Dimethoate & $0.0082 \pm 0.0001$ & 0.01 \\
\hline
\end{tabular}

EU MRL-maximum residue limits established by European Union, 2014. ${ }^{*}$ Pesticide residue above the MRL according to European Union. *Average of five replicates \pm standard deviation.

The processing techniques used in our studies including washing with tap water, washing with acetic acid solution $2 \%$, peeling and boiling. The behavior of 
insecticide residue concentration during processing and determination of processing factors (PFs), are shown in Table 6.

The effectiveness of each treatment depends on physico-chemical attributes of the studied pesticides, for instance, solubility in water $\left(S_{w}\right)$, the octanol-water partition coefficient $(\log P)$, the mode of action, boiling point and molecular mass (M), are presented in table 7 .

Variance analysis (ANOVA) was performed. The $\mathrm{P}$ value showed significant differences between the average concentrations of pesticides in the samples treated in the four processes.

The effectiveness of wishing with tap water resulted in $60 \%$ reduction for carbaryl, $47.39 \%$ for chlorpyrifos, $45.21 \%$ for dimethoate (average 3 samples),
$42.25 \%$ for 2,4 D (average 2 samples), $40.71 \%$ for cypermethrin (average 2 samples) and $40 \%$ for fenvalerate. Respectively, washing with tap water significantly minimized (up 40\%).

The correlation between the physicochemical features of the pesticides under study allow to explain our results. These properties include the solubility in water, the octanol-water partition coefficient and the PF values. It is to be noted that polar, water-soluble pesticides are more readily removed compared to lowpolarity materials. A number of studies have already reported that pesticides that are having low octanol-water partition coefficient are removed by washing more easily (Satpathy et al., 2012; Zhao et al., 2014; Kong et al., 2012).

Table 6 Effect of different household processing on the removal of pesticides residues exceeding MRL from the tested samples.

\begin{tabular}{|c|c|c|c|c|c|c|}
\hline \multirow[b]{2}{*}{$\begin{array}{l}\text { Sa } \\
\text { No. }\end{array}$} & \multirow{2}{*}{$\begin{array}{l}\text { Initial Residues } \\
\text { mg.kg-1 }\end{array}$} & \multicolumn{5}{|c|}{ Final Residues mg.kg ${ }^{-1} \pm \mathrm{SD}, \mathrm{PF}$} \\
\hline & & Tap Water & Acidic Solution & Peeling & Boiling & $\begin{array}{l}\text { ANOVA Test } \\
\text { ( P. value) }\end{array}$ \\
\hline 6 & $\begin{array}{l}\text { Dimethoate } \\
(0.089)^{\mathrm{a}}\end{array}$ & $\begin{array}{l}0.049 \pm 0.001^{\mathrm{b}} \\
\mathrm{PF}=0.55\end{array}$ & $\begin{array}{l}0.044 \pm 0.001^{\mathrm{c}} \\
\mathrm{PF}=0.49\end{array}$ & $\begin{array}{l}0.031 \pm 0.003^{\mathrm{d}} \\
\mathrm{PF}=0.35\end{array}$ & ND & 4.87E-08 \\
\hline 13 & $\begin{array}{l}\text { Carbaryl } \\
(0.13)^{\mathrm{a}}\end{array}$ & $\begin{array}{l}0.052 \pm 0.005^{\mathrm{bc}} \\
\mathrm{PF}=0.4\end{array}$ & $\begin{array}{l}0.048 \pm 0.012^{\text {bcd }} \\
\mathrm{PF}=0.34\end{array}$ & ND & $\begin{array}{l}0.038 \pm 0.007^{\mathrm{cd}} \\
\mathrm{PF}=0.29\end{array}$ & $9.73 \mathrm{E}-08$ \\
\hline 22 & $\begin{array}{l}\text { Dimethoate } \\
(0.07)^{\mathrm{a}}\end{array}$ & $\begin{array}{l}0.038 \pm 0.004^{\mathrm{bc}} \\
\mathrm{PF}=0.54\end{array}$ & $\begin{array}{l}0.035 \pm 0.011^{\mathrm{bc}} \\
\mathrm{PF}=0.5\end{array}$ & $\begin{array}{l}0.025 \pm 0.006^{\mathrm{d}} \\
\mathrm{PF}=0.36\end{array}$ & ND & $1.59 \mathrm{E}-07$ \\
\hline 26 & $\begin{array}{l}\text { Dimethoate } \\
(0.16)^{\mathrm{a}}\end{array}$ & $\begin{array}{l}0.088 \pm 0.012^{\mathrm{bc}} \\
\mathrm{PF}=0.55\end{array}$ & $\begin{array}{l}0.081 \pm 0.004^{\mathrm{bc}} \\
\mathrm{PF}=0.51\end{array}$ & $\begin{array}{l}0.058 \pm 0.012^{\mathrm{d}} \\
\mathrm{PF}=0.36\end{array}$ & ND & $1.59 \mathrm{E}-07$ \\
\hline 35 & $\begin{array}{l}\text { Chlorpyrifos } \\
(0.23)^{\mathrm{a}}\end{array}$ & $\begin{array}{l}0.121 \pm 0.022^{\mathrm{bc}} \\
\mathrm{PF}=0.53\end{array}$ & $\begin{array}{l}0.11 \pm 0.03^{\text {bcd }} \\
\mathrm{PF}=0.48\end{array}$ & ND & $\begin{array}{l}0.092 \pm 0.006^{\mathrm{cd}} \\
\mathrm{PF}=0.4\end{array}$ & $2.11 \mathrm{E}-08$ \\
\hline 44 & $\begin{array}{l}2,4 \mathrm{D} \\
(0.15)^{\mathrm{a}}\end{array}$ & $\begin{array}{l}0.087 \pm 0.024^{\mathrm{bc}} \\
\mathrm{PF}=0.58\end{array}$ & $\begin{array}{l}0.081 \pm 0.005^{\mathrm{bc}} \\
\mathrm{PF}=0.54\end{array}$ & $\begin{array}{l}0.046 \pm 0.007^{\mathrm{d}} \\
\mathrm{PF}=0.31\end{array}$ & ND & $2 \mathrm{E}-06$ \\
\hline 47 & $\begin{array}{l}\text { Fenvalerate } \\
(0.79)^{\mathrm{b}}\end{array}$ & $\begin{array}{l}0.474 \pm 0.051^{\mathrm{cd}} \\
\mathrm{PF}=0.6\end{array}$ & $\begin{array}{l}0.447 \pm 0.026^{\mathrm{cd}} \\
\mathrm{PF}=0.57\end{array}$ & ND & $\begin{array}{l}0.964 \pm 0.002^{\mathrm{a}} \\
\mathrm{PF}=1.22\end{array}$ & $2.84 \mathrm{E}-13$ \\
\hline 53 & $\begin{array}{l}\text { Cypermethrin } \\
(0.95)^{\mathrm{b}}\end{array}$ & $\begin{array}{l}0.561 \pm 0.041^{\mathrm{cd}} \\
\mathrm{PF}=0.59\end{array}$ & $\begin{array}{l}0.522 \pm 0.034^{\mathrm{cd}} \\
\mathrm{PF}=0.55\end{array}$ & ND & $\begin{array}{l}1.284 \pm 0.006^{\mathrm{a}} \\
\mathrm{PF}=1.35\end{array}$ & $2.11 \mathrm{E}-13$ \\
\hline 55 & $\begin{array}{l}\text { Cypermethrin } \\
(0.65)^{\mathrm{b}}\end{array}$ & $\begin{array}{l}0.387 \pm 0.033^{\text {cd }} \\
\mathrm{PF}=0.59\end{array}$ & $\begin{array}{l}0.358 \pm 0.054^{\mathrm{cd}} \\
\mathrm{PF}=0.55\end{array}$ & ND & $\begin{array}{l}0.895 \pm 0.005^{\mathrm{a}} \\
\mathrm{PF}=1.38\end{array}$ & $1.29 \mathrm{E}-13$ \\
\hline 65 & $\begin{array}{l}2,4 \mathrm{D} \\
(0.08)^{\mathrm{a}}\end{array}$ & $\begin{array}{l}0.046 \pm 0.022^{\mathrm{bc}} \\
\mathrm{PF}=0.57\end{array}$ & $\begin{array}{l}0.043 \pm 0.003^{\mathrm{bc}} \\
\mathrm{PF}=0.54\end{array}$ & $\begin{array}{l}0.025 \pm 0.004^{\mathrm{d}} \\
\mathrm{PF}=0.31\end{array}$ & ND & $4 \mathrm{E}-05$ \\
\hline
\end{tabular}

${ }^{*}$ Average of five replicates \pm SD standard deviation within each crop having the same letter are not significantly different at $\mathrm{P}<0.05 . \mathrm{PF}+\mathrm{Process}$ factor, $\mathrm{PF}<1$ reduction factor, $\mathrm{PF}>1$ concentration factor, (FAO/WHO 2012).ND _ Non-detectable.

Table 7 Physicochemical parameters and mode of action of pesticides

\begin{tabular}{lllllll}
\hline Pesticide & Group & Mode of action & $\log \boldsymbol{P}$ & $\mathbf{S}_{\mathbf{w}}$ & Boiling point $\left({ }^{\circ} \mathbf{C}\right)$ \\
\hline Dimethoate & Organophosphate & sys & 0.704 & 23800 & 310.3 & $\mathbf{M}$ \\
\hline Carbaryl & Carbamate & Non-sys & 1.59 & 120 & 366.5 & 229.3 \\
\hline Chlorpyrifos & Organophosphate & Non-sys & 4.7 & 1.05 & 395.8 & 201.2 \\
\hline 2,4 D & Phenoxy & sys & 2.59 & 890.1 & 345.6 & 350.89 \\
\hline Fenvalerate & Pyrethroid & Non-sys & 6.68 & 0.001 & 538.9 & 221.04 \\
\hline Cypermethrin & Pyrethroid & Non-sys & 5.5 & 0.004 & 826 & 419.91 \\
\hline
\end{tabular}

Boiling point $\left({ }^{\circ} \mathrm{C}\right)$ _ at $760 \mathrm{~mm} \mathrm{Hg}$. Sys_systemic pesticide. Non-sys_non-systemic pesticide. $\log P$ _octanol-water partition coefficient at $\mathrm{pH} 7,20{ }^{\circ} \mathrm{C}$.

$\mathrm{S}_{\mathrm{w}_{-}}$solubility in water at $20^{\circ} \mathrm{C}\left(\mathrm{mg} \cdot \mathrm{L}^{-1}\right)$. $\mathrm{M}_{-}$molecular mass $\left(\mathrm{g} \cdot \mathrm{mol}^{-1}\right)$.

In our study, a gradual depression was noted when octanol-water partition coefficient decreased and solubility in water increased. But this did not have an impact on the leverage of washing in all cases, as in the case of dimethoate and 2,4 D.This is because of the high polarity of these pesticides and their being systemic pesticides. That can be absorbed through the fruit. In addition to that the inside of tomato is more polar because of the high content of water. This explains the tendency of polar pesticides to diffuse through the tomatoes peel, which is also assured by our results despite their high water solubility. Similar conclusions were obtained by Lozowicka et al. (2016). The authors found that acetamiprid, with a $\operatorname{low} \log P=0.8$ and high solubility in water $2950 \mathrm{mg} . \mathrm{L}^{-1}$ presented a low $P F=0.43$. Compared to deltamethrin $\left(\log P=4.6, S_{w}=0.0002 \mathrm{mg} . \mathrm{L}\right.$ $\left.{ }^{1}\right) \mathrm{PF}=0.73$. While on the other hand, bupirimate and pirimicarb (with a systemic mode of action), despite their high water solubility, are more unlikely to be moved into the pulp of strawberries. Thus, they offered $\mathrm{PF}=0.80$ and $\mathrm{PF}=0.79$.

Comparing the above results, it is observed that acetic acid solution is more efficacious than tap water for pesticide elimination. This process reduced the level of pesticides by $43.42 \%$ to $63.08 \%$. This is due to the fact that the percentage of dissolution of the pesticides increases at upper $\mathrm{pH}$. A similar finding was reported by Abou-Arab (1999), who showed that the rate of loss of different pesticides (pirimiphos-methy, lindane, dimethoate, p-DDT, profenofos and $\mathrm{HCB}$ ) depended on the concentration levels of acetic acid and $\mathrm{NaCl}$ solutions on tomatoes. As well Radwan et al.(2005) found that the most active removal from eggplant and sweet pepper happened by acetic acid solution.

Peeling also had great effectiveness in targeting surface pesticides. Even those non-polar pesticides, which have been less effective in washing. The outer and waxy layer may have significant utilities in physically protecting fruit from the presence of harmful pesticides (Kimbara et al., 2012). Peeling off the tomatoes was found to totally remove the residues of cypermethrin, carbaryl, chlorpyrifos and fenvalerate. More efficiently compared to 2,4 D and dimethoate. The rate of residues removed to 69.04 and $64.34 \%$ through the peeling process. This was expected, as chlorpyrifos, carbaryl, cypermethrin and fenvalerate are nonsystemic insecticides, and hence they do not pass to plant tissue. Whereas, 2, $4 \mathrm{D}$ and dimethoate are systemic, rendering them move inside the plant. A similar observation was found by Boulaid et al.(2005) who noted that the rate of pesticide residues excluded through the peeling process was $70 \%$ to $100 \%$ in tomatoes, and Awasthi (1993) found that Peeling removed 100\% of the residues for fenvalerate and cypermethrin.

As shown in Table 6, the levels of the studied pesticides are highly lowered during the boiling. This process generated a greater decrease for most pesticides than do both types of washing and peeling. The reduction of pesticide residue during thermal processing can be caused by evaporation, hydrolysis and codistillation which differ with the chemical structure of the pesticide (Sharma et al., 2005). However, the results achieved by the heat treatment showed that complete removal of 2,4D and dimethoate residues were finally achieved by boiling of tomatoes (below of LOQ). There was a $70.77 \%$ reduction after boiling for carbaryl. While chlorpyrifos showed the lowest $(60 \%)$. In addition to that concentrations of cypermethrin and fenvalerate (pyrethroid insecticides) increased, and processing factors higher than 1 were observed. These results are due to the concentration of these pesticides in water evaporated from the tomatoes during process. Similarly, with our findings, Lozowicka et al. (2016) found that the boiling results indicate that residues of three pesticides from the pyrethroid group (alpha-cypermethrin_( $\mathrm{PF}=1.02,1.66$ and 1.76), deltamethrin $(\mathrm{PF}=1.03,1.16$ and 1.32) and in addition lambda-cyhalothrin $(\mathrm{PF}=1.19,1.38$ and 1.70)) increased in strawberries. Also, Rasmusssen et al. (2003) found that the boiling did not minimize the pesticide residues in apples.

As shown in Table 6,boiling efficiency in dispersing pesticides residues may be interpreted by increasing solubility and at the same time by reducing boiling point of the pesticide, such as dimethoate $\left(\mathrm{S}_{\mathrm{w}} 23800 \mathrm{mg} . \mathrm{L}^{-1}\right.$, boiling poin $\left.310.3^{\circ} \mathrm{C}\right)$ and $2,4 \mathrm{D}\left(\mathrm{S}_{\mathrm{w}} 890.1 \mathrm{mg} . \mathrm{L}^{-1}\right.$, boiling point $\left.345.6^{\circ} \mathrm{C}\right)$ were significantly removed (less than LOQ) in contrast with cypermethrin $\left(\mathrm{S}_{\mathrm{w}} 0.004 \mathrm{mg} . \mathrm{L}^{-1}\right.$, boiling 
point $\left.826^{\circ} \mathrm{C}, \mathrm{PF}>1\right)$ and fenvalerate $\left(\mathrm{S}_{\mathrm{w}} 0.001 \mathrm{mg} . \mathrm{L}^{-1}\right.$, boiling point $538.9^{\circ} \mathrm{C}$, $\mathrm{PF}>1)$.Lee and Lee(1997) indicated that $45 \%$ of chlorpyrifos residues were excluded when foods are washed in water, $56 \%$ with acidic solution washing, $51 \%$ with boiling and $91 \%$ with peeling. This was almost identical to our finding for chlorpyrifos.

Fig 6 shows the concentration modifications of the pesticides residue levels during processing, for 2,4 $\mathrm{D}$ and dimethoate, boiling played the biggest role in reducing their residues, followed by peeling, then washing with acetic acid $2 \%$ and then washing with tap water. As for carbaryl and chlorpyrifos, it was shown that processing techniques are in the following order: peeling >boiling $>$ washing with acetic acid> washing with tap water, on other hand, peeling played effective role in removing residues from samples for cypermethrin and fenvalerate, followed by washing with acetic acid solution and then washing with tap water But boiling was counterproductive by increasing the concentrations of their residues.

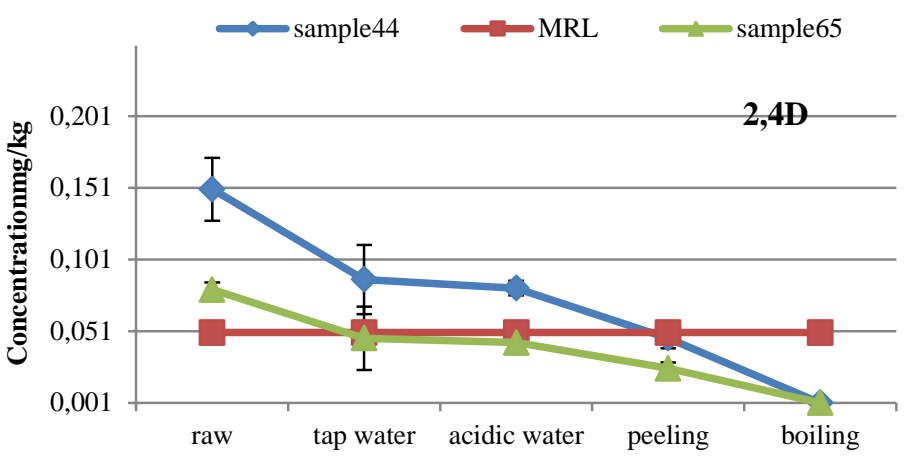

Household processing
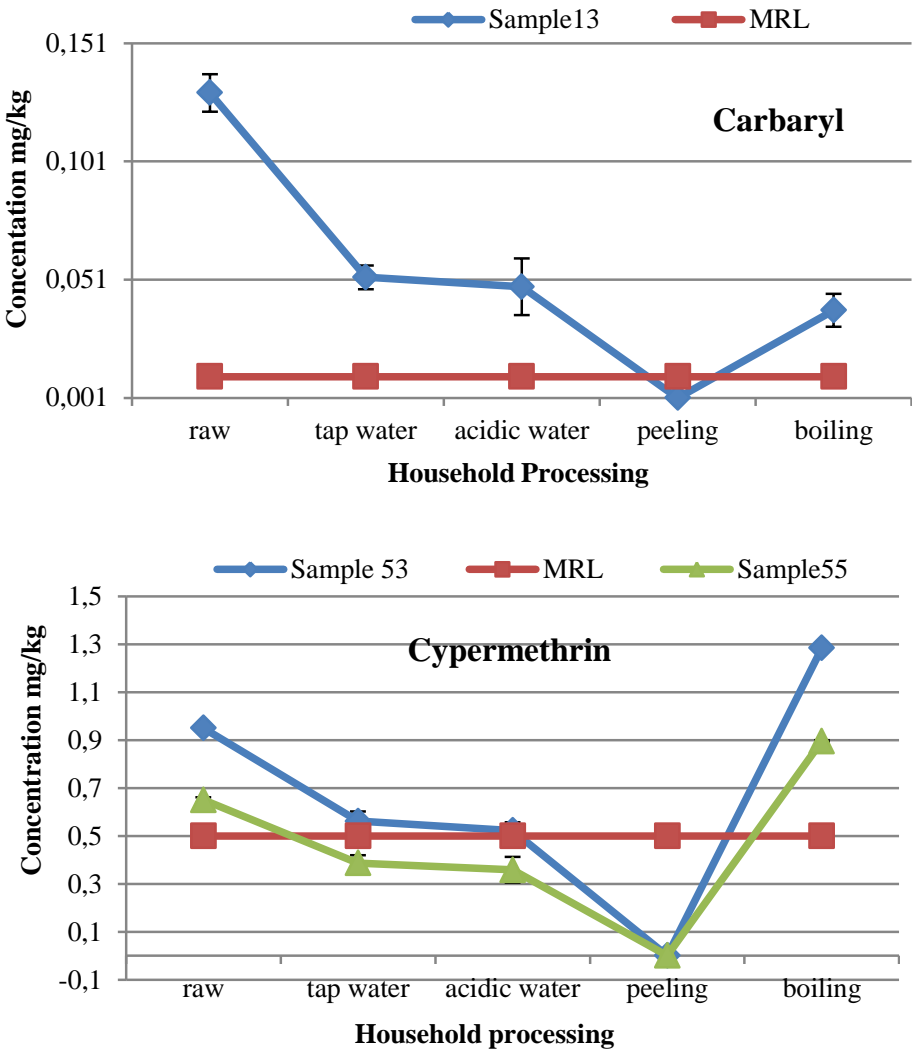

Household processing
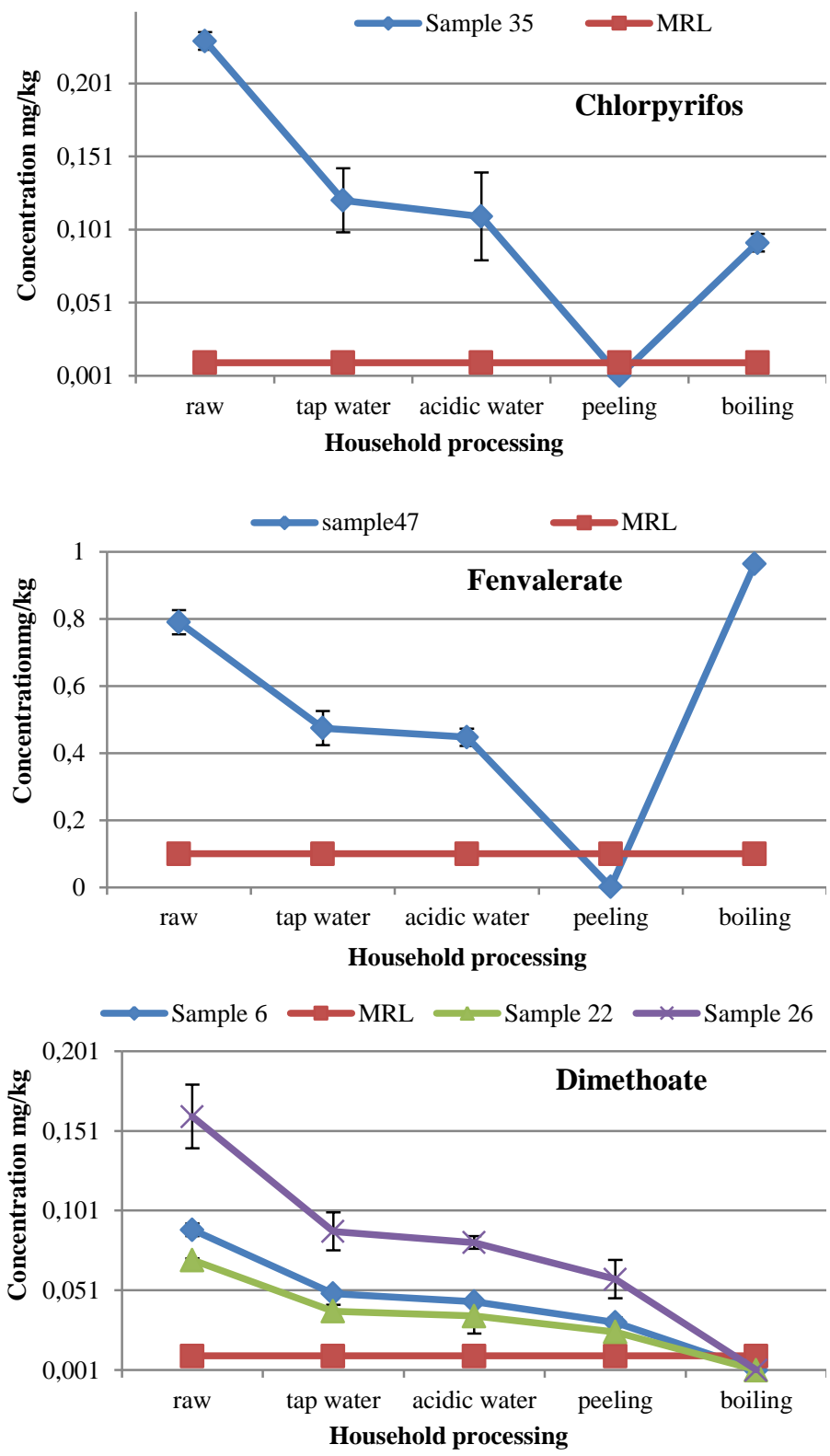

Figure 6 Pesticide behavior during processing in tomatoes

\section{CONCLUSION}

In the present study, tomatoes samples (72) were collected from 3 central markets and analyzed for 22 pesticides. Of all analyzed samples, $47.22 \%$ included studied residues, of which $13.89 \%$ exceeded the maximum residue limits, and 8 pesticides belonging to the different chemical category were detected.

The effects of washing with tap and acetic acid solution, peeling and boiling on 6 pesticides (five insecticides and one herbicide) residue levels in raw tomatoes were examined to evaluate the efficacy of processing on pesticides. Processing factors associated to each process were calculated. Processing factors were, in general, below 1 for most of the pesticides under study. Only after accomplishing the boiling process, two pesticides (cypermethrin and fenvalerate) offer PFs above 1. Both of two washings lowered residues for all detected pesticides with removal of up to $63.08 \%$. Washing with acetic acid solution was demonstrated to be more effective than washing with tap water. Peeling off the tomatoes was found to totally remove the residues of cypermethrin, carbaryl, chlorpyrifos and fenvalerate. Results obtained from the thermal process indicated that complete removal of 2,4D and dimethoate residues were finally achieved by boiling of tomatoes (below of LOQ). Although the boiling process will change the sensory profile of the product, it is important to know the effectiveness of this process and know the dietary intake of pesticides after boiling vegetables; especially it is a common process in our daily food. In general, all processing factors were explained by solubility in water, boiling point, octanol-water partition coefficient and the mode of action of the studied pesticides. Moreover, washing vegetables and fruits before using has to be strictly considered by the consumer. 
This study provided information which may be important to determine the MRL for raw tomatoes and processed commodities, for instance tomato paste or juice. Clearly, the reduction of the levels and frequency of pesticides in food will improve consumer confidence in the safety of fresh products. It is an importan and a solid step in the right direction in promoting better and healthier dietary consumption patterns. With the growing need to identify food safety risks, such research becomes vital and critical for a more actual and accurate assessment of the dietary intake of the pesticides.

\section{REFERENCES}

ABOU-ARAB, A.A.K. 1999. Behavior of pesticides in tomatoes during commercial and home preparation. Food Chemistry, 65(4), 509 514.http://dx.doi.org/10.1016/s0308-8146(98)00231-3

AGUILERA, A., VALVERDE, A., CAMACHO, F., BOULAID, M., GARCIAFUENTES, L. 2012. Effect of household processing and unit to unit variability of azoxystrobin, acrinathrin and kresoxim methyl residues in zucchini. Food Control, 25(2), 594-600.http://dx.doi. org/10.1016/j.foodcont.2011.11.038 ALAVANJA, M.C.R., ROSS, M.K., BONNER, M.R. 2013. Increased cancer burden among pesticide applicators and others due to pesticide exposure. Cancer J, Clin, 63(2), 120-142. http://dx.doi.org/10.3322/caac.21170

AMVRAZI, EG. 2011. Fate of pesticide residues on raw agricultural crops after postharvest storage and food processing to edible portions. Pesticides formulations, fate. Margarita Stoytcheva, IntechOpen.http://www.intechopen.com/books/pesticidesformulations-effectsfate/fate-of-pesticide-residues-on-raw-agricultural-crops-after-postharveststorage-and-food-processing-t. Accessed 13 May 2015.

AWASTHI, MD. 1993. Decontamination of insecticide residues on mango by washing and peeling. J Food Sci Technol, 30(2)132-133.

BEMPAH, C. K., DONKOR, A., YEBOAH, P. O., DUBEY, B., OSEI-FOSU, P. 2011. A preliminary assessment of consumer's exposure to organochlorine pesticides in fruits and vegetables and the potential health risk in accra metropolis, ghana. Food chemistry, 128 (4), 1058-65.

https://dx.doi.org/10.1016/j.foodchem.2011.04.013

BONNECHERE, A., HANOT, V., BRAGARD, C., BEDORET, T., VAN LOCO, J. 2012. Effect of household and industrial processing on the levels of pesticide residues and degradation products in melons. Food Addit Contam. A Chem. Anal Control Expo Risk Assess, 29(7),1058-1066. http://dx.doi/10. 1080/19440049.2012.672339

BOULAID, M., AGUIIERA, A., CAMACHO, F., SOUSSI, M., VALVERDE, A 2005. Effect of household processing and unit-to-unit variability of pyrifenox, pyridaben and tralomethrin residues in tomatoes. Journal of Agricultural and Food Chemistry, 53(10), 4054-4058. https:// dx.doi.org/10.1021/jf040455y

CABRAS, P. AND ANGIONI, A. 2000. Pesticide residues in grapes, wine, and their processing products. Journal of Agricultural and Food Chemistry, 48(4), 967-973.https://dx.doi.org/10.1021/jf990727a

CERTEL, M., CENGIZ, MF., AKCAY,M. 2011. Kinetic and thermodynamic investigation of mancozeb degradation in tomato homogenate during thermal

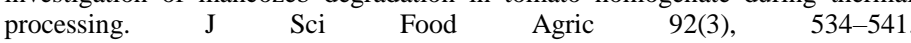
https://dx.doi.org/10.1002/jsfa.4603

CODEX ALIMENTARIUS. 2000. Food Standards Programme, Pesticide Residues in Food, Methods of analysis and sampling. Volume 2A Part 1. World Health Organization.

COLUME, A., CARDENAS, S., GALlEGO, M., VAlCARCEL, M. 2001a Multiresidue screening of pesticides in fruits using an automatic solid phase extraction system. Journal of Agriculture and Food Chemistry, 49(3), 11091116.https://dx.doi.org /10.1021/jf0011687

COLUME, A., CARDENAS, S., GALLEGO, M., VALCARCEL, M. 2001b. Semiautomatic multiresidue gas chromatographic method for the screening of vegetables for 25 organochlorine and pyrethroid pesticides. Journal of Analytica Chimica Acta, 436(1) 153-162. https://dx.doi.org/ 10.1016/S00032670(01)00901-1

EUROPEAN COMMISSION, Food safety, Neonicotinoids Pesticides.2018 Available online http://ec.europa.eu/food/plant / pesticides /approval active substances/approval renewal/ neonicotinoids en.

EUROPEAN COMMISSION, Max Residue Levels MRLs Database of Pesticides.Accessed 12 November 2014 http://ec.europa.eu sanco pesticides/ public/?event=homepage.

EUROPEAN COMMISSION. Method Validation and Quality Control Procedures for Pesticide Residues Analysis in Food and Feed.2016. Available online http://ec.europa.eu/food/plant/protection/ resources / qualcontrol_en. pdf (accessed on 10 October 2016).

EUROPEAN STANDARD.2008. EN 15662:2008. Foods of plant origin Determination of pesticide residues using GC-MS and/or LC-MS/ MS following acetonitrile extraction/partitioning and clean-up by dispersive SPE - Quechersmethod

FAO/WHO.2012. Updating the principles and methods of risk assessment: MRLs for pesticides and veterinary drugs: FAO; Rome

HAN, D., TANG, B., TIAN, M., ROW, KH. 2013.Solid-phase extraction combined with dispersive liquid-liquid microextraction for the determination of three benzimidazole pesticides (carbendazim, thiabendazole, and thiophanatemethyl) in tomatoes. Anal Lett 46(4) 557-568 https://dx.doi.org/10.1080/00032719.2012.726682

JANKOWSKA, M., KACZYNSKI, P., HRYNKO, I., LOZOWICKA, B. 2016 Dissipation of six fungicides in greenhouse-grown tomatoes with processing and health risk. Environ Sci Pollut Res 23(12)11885-11900. https://dx.doi.org/10.1007/s11356-016-6260-x

KEIKOTLHAILE, B.M., SPANOGHE, P., STEURBAUT, W. 2010. Effects of food processing on pesticide residues in fruits and vegetables: a meta analysis approach. Food Chem Toxicol 48(1),1-6. https://dx.doi.org/10.1016/j.fct. 2009.10.031

KIMBARA, J., YOSHIDA, M., ITO, H., HOSOI, K., KUSANO, M. KOBAYASHI, M., ARIIZUMI, T., ASAMIZU, E., EZURAAL, H. 2012. A novel class of sticky peel and light green mutations causes cuticle deficiency in leaves and fruits of tomato (Solanum lycopersicum). Planta 236(5), 1559-1570. https://dx.doi.org/10.1007/s00425-012-1719-6

KONG, Z. Q., DONG, F. S., XU, J., LIU, X. G., LI, J., \& LI, Y. B. 2012. Degradation of acephate and its metabolite methamidophos in rice during processing and storage. Food Control, 23(1), 149-153. https://dx.doi.org/10.1016/j.foodcont.2011.07.001

LEE, MG.and LEE, SR.1997.Reduction factors and risk assessment of organophosphorus pesticides in Korean foods. Korean J Food Sci Technol, 29(2), 240-248.

LEHOTAY, S. J. 2007. Determination of pesticide residues in foods by acetonitrile extraction and partitioning with magnesium sulfate: collaborative study. Journal of AOAC International, 90(2), 485-520.

LEHOTAY, S.J., HIEMSTRA, M., VAN BODEGRAVEN, P., DE KOK, A 2005. Validation of a fast and easy method for the determination of more than 200 pesticide residues in fruits and vegetables using gas and liquid chromatography and mass spectrometric detection. J, AOAC Int, 88(2), 595-614 LI, Y., JIAO, B., ZHAO, Q., WANG, C., GONG, Y., ZHANG, Y., CHEN,W. 2011. Effect of commercial processing on pesticide residues in orange products. Eur Food Res Technol, 234(3), 449-456. https://dx.doi.org/10.1007/s00217011-1651-1

LOZOWICKA, B. 2015. Health risk for children and adults consuming apples with pesticide residue. Sci. Total Environ, 502, 184-198. https://dx.doi.org/10.1016/j.scitotenv.2014.09.026

LOZOWICKA, B., ABZEITOVA, E., SAGITOV, A., KACZYNSKI, P., TOLEUBAYEV, K., LI, A. 2015. Studies of pesticide residues in tomatoes and cucumbers from Kazakhstan and the associated health risks. Environ Monit Assess, 187(10),609 https://dx.doi.org/10.1007/s10661-015-4818-6.

LOZOWICKA, B., JANKOWSKA, M., HRYNKO, I., KACZYNSKI, P.2016. Removal of 16 pesticide residues from strawberries by washing with tap and ozone water, ultrasonic cleaning and boiling.Environmonit Assess, 188(1):51.https://dx.doi.org/10.1007/s10661-015-4850-6

PICO, Y., LA FARRE, M., SOLER, C., BARCELO, D.2007. Identification of unknown pesticides in fruits using ultra performance liquid chromatography quadruple time of flight mass spectrometry. Imazalil as a case study of

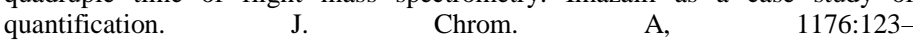
134.https://dx.doi.org/10.1016/j.chroma.2007.10.071.

RADWAN, M.A., ABU-ELAMAYEM, M.M., SHIBOOB, M.H., ABDEL-AAL, A. 2005. Residual behaviour of profenofos on some field-grown vegetables and its removal using various washing solutions and household processing. Food Chem Toxic, 43:553-557. https://dx.doi.org/10.1016/j.fct.2004.12.009

RASMUSSSEN, R. R., POULSEN, M. E., \& HANSEN, H. C. B.2003.Distribution of multiple pesticide residues in apple segments after home processing. Food Additives \& Contaminants, 20(11), 1044-1063 https://dx.doi.org/10.1080/02652030310001615221

RAWN, D. F. K., QUADE, S. C., SUN, W., FOUGUET, A., BELANGER, A. SMITH, M.2008. Captan residue reduction in apples as a result of rinsing and $\begin{array}{llll}\text { peeling. } & \text { Food } & \text { 790-796 }\end{array}$ https://dx.doi.org/10.1016/j.foodchem.2008.01.061

ROHAN,D., SIDDHARTH,T., PADMAJA,N. 2012. Pesticide residue analysis of fruits and vegetables, Journal of Enviromental chemistry and Ecotoxicology.4(2),19-28.https://dx.doi.org/10.5897/JECE11.072

SALGHI, R., LUIS, G., RUBIO, C., HORMATALlAH, A., BAZZI, L., GUTIERREZ, A.J., HARDISSON, A.2012. Pesticide residues in tomatoes from greenhouses in Souss Massa Valley, Morocco. Bull Environ Contam Toxicol, 88(3)358-361. https://dx.doi.org/10.1007/s00128-011-0503-9.

SATPATHY, G., TYAGI, Y.K., GUPTA, R.K.2012. Removal of organophosphorus(OP) pesticide residues from vegetables using washing $\begin{array}{lllll}\text { solutions and } & \text { boiling. } & \text { J } & \text { Agr } & \text { Sci,4(2),69-78 }\end{array}$ https://dx.doi.org/10.5539/jas.v4n2p69

SHABEER, A. T. P., KAUSHIK, B., MANJUSHA, J., RUSHALI, G., SAGAR, U., SANDIP, H., DASHARATH, O. 2015. Residue dissipation and processing factor for dimethomorph, famoxadone and cymoxanil during raisin preparation. Food Chemistry, 170,

https://dx.doi.org/10.1016/j.foodchem.2014.08.008.

SHARMA, J., SATYA, S., KUMAR, V., TEWARY, D.K.2005.Dissipation of pesticides during breadmaking. J Chem Health Safety, 12, 17-22. 
STEEL, R.C.D., TORRIE, J.H. 1980. Principles and Procedures of Statistics: A Biometrical Approach, second ed. Mc-Graw Hill Kogakusha Ltd., Hill book company, New York, 633.

TAHIR, M. U., NAIK, S. I., REHMAN, S., SHAHZAD, M. 2009. A Quantitative Analysis for the Toxic Pesticide Residues in Marketed Fruits and Vegetables in Lahore, Pakistan. Biomedica, 25(23), 171-174.

TORRES, C. M., PICO, Y., MANES, J.1997. Comparison of octadecylsilica and graphitized carbon black as materials for solid-phase extraction of fungicide and insecticide residues from fruit and vegetables. Journal of Chromatography A, 778(1-2), 127-137. https://dx.doi.org/10.1016/ S0021-9673(97)00287-2

TORRES, C.M., PICO,Y., MANES, J.1996.Determinationof pesticide residues in fruit and vegetables. Journal of Chromatography A, 754(1-2), 301-331.

UCLES, S., BELMONTE, N., MEZCUA, M., MARTINEZ, A.B., MARTINEZ-

BUENO, M.J., GAMON, M., FERNANDEZ-ALBA, A.R.2014, Validation of a multiclass multiresidue method and monitoring results for 210 pesticides in fruits and vegetables by gas chromatography-triple quadrupole mass spectrometry. J

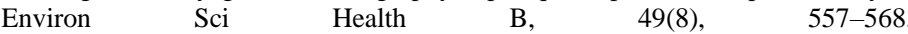
https://dx.doi.org/10.1080/03601234.2014.911566

ZAWIYAH, S., CHE MAN, Y.B., NAZIMAH,S.A.H., CHIN, C.K., TSUKAMOTO, I., HAMANYZA, A.H., NORHAIZAN, I. 2007. Determination of organochlorine and pyrethroid pesticides in fruit and vegetables using SAX/PSA clean-up column, Food Chemistry, 102, 98-103. https://dx.doi.org/10.1016/j.foodchem.2006.05.003

ZHAO, L., GE, J., LIU, F., JIANG, N. 2014. Effects of storage and processing on residue levels of chlorpyrifos in soybeans. Food Chemistry, 150, 182186.https://dx.doi.org/10.1016/j.foodchem. 2013.10.124 